\title{
Environmental Tin Exposure in a Nationally Representative Sample of U.S. Adults and Children: the National Health and Nutrition Examination Survey 2011-2014
}

\author{
Hans-Joachim Lehmler ${ }^{1}$, Manuel Gadogbe ${ }^{1}$, Buyun $\mathrm{Liu}^{2}$, and Wei Bao ${ }^{2}$ \\ ${ }^{1}$ Department of Occupational \& Environmental Health, College of Public Health, University of \\ lowa, lowa City, IA, United States \\ 2Department of Epidemiology, College of Public Health, University of lowa, lowa City, IA, United \\ States
}

\section{Abstract}

Tin is a naturally occurring heavy metal that occurs in the environment in both inorganic and organic forms. Human exposure to tin is almost ubiquitous; however, surprisingly little is known about factors affecting environmental tin exposure in humans. This study analyzed demographic, socioeconomic and lifestyle factors associated with total urinary tin levels in adults $(\mathrm{N}=3,522)$ and children $(\mathrm{N}=1,641)$ participating in the National Health and Nutrition Examination Survey (NHANES) 2011-2014, a nationally representative health survey in the United States. Urinary tin levels, a commonly used biomarker of environmental tin exposure, were determined by inductively coupled plasma mass spectrometry (ICP-MS). Detection frequencies of tin were $87.05 \%$ in adults and $91.29 \%$ in children. Median and geometric mean levels of urinary tin in the adult population were $0.42 \mu \mathrm{g} / \mathrm{L}$ and $0.49 \mu \mathrm{g} / \mathrm{L}$, respectively. For children, median and geometric mean levels of urinary tin were $0.60 \mu \mathrm{g} / \mathrm{L}$ and $0.66 \mu \mathrm{g} / \mathrm{L}$, respectively. Age was identified as an important factor associated with urinary tin levels. Median tin levels in the $\geq 60$ year age group were almost 2 -fold higher than the 20-39 year age group. Tin levels in children were 2-fold higher than in adolescents. Race/ethnicity and household income were associated with tin levels in both adults and children. In addition, physical activity was inversely associated with urinary tin levels in adults. These results demonstrate that total tin exposures vary across different segments of the general U.S. population. Because the present study does not distinguish between organic and inorganic forms of tin, further studies are needed to better characterize modifiable factors associated with exposures to specific tin compounds, with the goal of reducing the overall exposure of the U.S. population.

\section{Graphical abstract}

Corresponding Author: Wei Bao, MD, PhD, Department of Epidemiology, College of Public Health, University of Iowa, $145 \mathrm{~N}$. Riverside Drive, Room S431 CPHB, Iowa City, IA 52242, USA, Tel: 319-384-1546, Fax: 319-384-4155, wei-bao@uiowa.edu. Publisher's Disclaimer: This is a PDF file of an unedited manuscript that has been accepted for publication. As a service to our customers we are providing this early version of the manuscript. The manuscript will undergo copyediting, typesetting, and review of the resulting proof before it is published in its final citable form. Please note that during the production process errors may be discovered which could affect the content, and all legal disclaimers that apply to the journal pertain. 


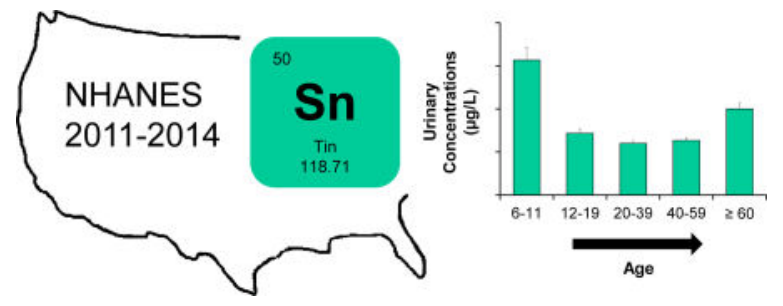

\section{Keywords}

Urinary tin; human exposure; U.S. population

\section{Introduction}

Tin is a naturally occurring element that is found in both inorganic and organic forms in the environment. It is classified by the WHO as potentially toxic (WHO, n.d.-a). Acute health effects associated with exposure to inorganic tin, in particular the consumption of food products contaminated with high levels of tin, include acute gastrointestinal illnesses (reviewed in: Blunden and Wallace, 2003; Ostrakhovitch, 2014). In humans, the severity of adverse gastrointestinal effects are not necessarily associated with the tin levels, but with the chemical form of tin present in foodstuff (Boogaard et al., 2003). Studies investigating a link between chronic, low level exposures to inorganic tin and adverse human health outcomes are limited. A cross-sectional study reported a positive but non-significant association between urinary tin concentration and diabetes (Feng et al., 2015). In coke oven workers in China, urinary tin levels were associated with elevated fasting plasma glucose levels (Liu et al., 2016). Further studies are therefore needed to assess if low level, chronic exposures to inorganic forms of tin are associated to adverse outcomes in humans. In contrast to inorganic tin, organotin compounds are considered more toxic, and several organotin compounds, in particular tributyltin, have been identified by laboratory studies as environmental obesogens (Grün, 2010; Heindel et al., 2017; Zuo et al., 2011). Epidemiological studies of adverse outcomes associated with exposure to organotin compounds are also limited, and suggest a link between organotin compounds and adverse developmental outcomes (Rantakokko et al., 2013, 2014).

The total global production of tin reached 265,000 tons in 2010, and slightly decreased to 253,000 tons in 2011 (Survey, 2010). A 2017 survey estimates that 422,900 tons of tin were used globally in 2016 (ITRI, 2017). Tin is used in a range of industrial and consumer applications, including tin-plated food and beverage cans, containers, electrical equipment, and transportation and construction materials. Inorganic tin compounds are also used in the glass and ceramic industries, and for the formulation of soaps and perfumes. Stannous chloride $\left(\mathrm{SnCl}_{2}\right)$ is the most frequently used form of inorganic tin, and it is listed by the United States Food and Drugs Administration as a Generally Regarded as Safe (GRAS) food additive for human consumption (FDA, n.d.). Organotin compounds were used as stabilizers for polyvinyl chloride (PVC), biocides, and catalysts for the synthesis of polyurethanes and silicones (ENVISA, n.d.); however, the production and use of organotin compounds for 
many applications, such as anti-fouling paints used on ships, are now banned globally (ENVISA, n.d.; IMO, n.d.).

Inorganic tin is released into the environment from both natural and anthropogenic sources. In contrast, organotin compounds are mainly released from anthropogenic sources (ATSDR, n.d.; Carlin Jr, n.d.; Ostrakhovitch, 2014). Inorganic tin is considered relatively immobile in the environment according to the Agency for Toxic Substances and Disease Registry (ATSDR, n.d.). Human exposures can occur by inhalation, ingestion, or dermal absorption (WHO, n.d.-c). Consumption of food, in particular canned food and beverages, is considered to be a major source of exposure of humans to inorganic forms of tin (Blunden and Wallace, 2003; Ostrakhovitch, 2014; WHO, n.d.-a). Dietary intake levels of inorganic tin from canned foods can vary widely because tin levels in canned food are, for example, affected by the use of lacquered vs. unlacquered cans, the acidity of the food, storage conditions, and the presence of agents that influence the extent of tin dissolution from the tin coating (Greig and Pennington; IPCS). Interestingly, several studies reported that the consumption of canned food is not associated with urinary tin levels (Hayashi et al., 1991; Shimbo et al., 2007; Shimbo et al., 2013; Yang et al., 2015). Diet is also a major route of exposure to organotin compounds. Seafood accounts for a majority of intake of organotin compounds (Airaksinen et al., 2010; Choi et al., 2012; Filipkowska et al., 2016; Guérin et al., 2007); however, a recent analysis of diet samples from Portugal demonstrates that for the majority of samples the estimated daily intakes of organotin compounds were below the tolerable daily intake of $100 \mathrm{ng} / \mathrm{kg} / \mathrm{d}$ (Sousa et al., 2017).

Tin was detected with a $36 \%$ frequency in a small, recent survey of treated drinking water samples from the United States (Glassmeyer et al., 2017), with median and maximum tin levels of $6.4 \mu \mathrm{g} / \mathrm{L}$ and $15.9 \mu \mathrm{g} / \mathrm{L}$, respectively. These levels are comparable to tin levels reported for drinking water in earlier studies and suggest that drinking water in not a significant source of tin exposure in the general population (Schroeder et al., 1964; WHO, n.d.-c). Similarly, air makes only a small contribution to the daily intake of tin in the general population (Schroeder et al., 1964; WHO, n.d.-c). Occupational exposures can result in an increased exposure to tin, as assessed using urinary tin levels (Julião et al., 2007; Liu et al., 2016). Inorganic tin is poorly adsorbed by humans, with only $3 \%$ of inorganic tin being absorbed from a diet supplemented with $50 \mathrm{mg}$ tin per day (Johnson and Greger, 1982). Studies in rats and human subjects show that feces is the major route of excretion of inorganic tin following oral exposure, mostly because of the poor absorption of tin in the gastrointestinal tract (Benoy et al., 1971; Calloway and McMullen, 1966; Hiles, 1974; Winship, 1988). However, based on animal studies, inorganic tin is primarily eliminated from the systemic circulation via the urine (Hiles, 1974; Mance et al., 1988). Several factors, such as the route of administration, the dose and the form of tin, may explain differences in the fecal vs. urinary excretion of tin observed in animal studies (Hiles, 1974). Like inorganic forms of tin, organotin compounds can also be absorbed in the gastrointestinal tract and are eliminated with the feces, bile or urine in a manner that is highly compound specific.

Overall, there is contemporary exposure of humans to both inorganic and organic forms of tin. Dietary intake of tin is influenced by several factors, such as age and the consumption of food and beverages contaminated with tin compounds. However, factors influencing the 
urinary elimination of both inorganic and organic forms of tin, and thus the toxicologically relevant internal tin dose, have not been investigated previously in the general U.S. population. Here, we analyzed associations between potential demographic, socioeconomic and lifestyle factors and urinary levels of total tin determined by ICP-MS in U.S. adults and children participating in NHANES 2011-2014, a nationally representative health survey in the United States.

\section{Materials and Methods}

\subsection{NHANES survey}

NHANES is a nationally representative survey of the non-institutionalized U.S. population that is administered by the National Center for Health Statistics at the Centers for Disease Control and Prevention (CDC) (CDC, n.d.-a). The survey collects a broad range of information, for example on the demographics, socioeconomic status, diet, lifestyle, and medical conditions, performs extensive health examinations, and collects specimens for laboratory tests from study participants. NHANES data are released in 2-year cycles. NHANES has been approved by the National Center for Health Statistics Ethics Review Board and written informed consent is obtained from all participants. Additional information about NHANES is available elsewhere (CDC, n.d.-a). For this study, we analyzed data from the NHANES 2011-2012 and 2013-2014 cycles, because tin levels were only measured in these two cycles. The final study population consisted of 5,163 participants (children and adults) who had data available on urinary tin concentrations.

\subsection{Total tin analysis}

Concentrations of total tin in urine samples were measured using ICP-MS at the Inorganic and Radiation Analytical Toxicology Division of Laboratory Sciences, National Center for Environmental Health, CDC. Briefly, all urine samples as well as blanks, calibrators, and QC samples were diluted 1:9 $(\mathrm{V} / \mathrm{V})$ with a diluent containing $10 \mu \mathrm{g} / \mathrm{L}$ of the internal standards iridium and rhodium for multi-internal standardization and $500 \mu \mathrm{g} / \mathrm{L}$ gold in $2 \%$ $(\mathrm{v} / \mathrm{v})$ nitric acid prior to analysis. The analysis of total tin in the urine samples was performed in the standard mode using an ELAN DRC II ICP-MS equipped with an ESI SC4-DX auto sampler. The lower limit of detection (LLOD) of the urinary tin analysis was $0.090 \mu \mathrm{g} / \mathrm{L}[40]$. For urinary tin levels below the LLOD, an imputed fill value was assigned by CDC staff as the LLOD divided by square root of 2 .

\subsection{Potential factors influencing urinary tin levels}

Information on age, gender, race/ethnicity, education, family income, smoking status, alcohol intake, physical activity, and medical conditions was collected by NHANES using standardized questionnaires. Race/ethnicity was categorized as non-Hispanic white, nonHispanic black, Hispanic (Mexican and non-Mexican Hispanic), and other race/ethnicity. Education was grouped as less than high school, high school, and college or higher. Family income-to-poverty ratio (PIR) was categorized as $\leq 1.30,1.31-3.50$, and $>3.50$ (Johnson et al., 2013; Liu et al., 2017). Education was grouped as less than high school, high school, and college or higher. Adults who smoked less than 100 cigarettes in their lifetime were defined as never smokers; those who had smoked more than 100 cigarettes but did not smoke at the 
time of survey were considered former smokers; and those who had smoked more than 100 cigarettes and smoked cigarettes at the time of survey were defined as current smokers (Liu et al., 2017). Alcohol intake was categorized as $0 \mathrm{~g} / \mathrm{d}, 0.1-27.9 \mathrm{~g} / \mathrm{d}, \geq 28 \mathrm{~g} / \mathrm{d}$ for male, and 0 $\mathrm{g} / \mathrm{d}, 0.1-13.9 \mathrm{~g} / \mathrm{d}, \geq 14 \mathrm{~g} / \mathrm{d}$ for female. Physical activity was assessed by the Global Physical Activity Questionnaire, and metabolic equivalents of task (MET) minutes per week were derived to take into account both the duration and intensity of different activities [43]. Weight and height were measured by trained health technicians, and the BMI was calculated as weight in kilograms divided by height in meters squared. The BMI was classified as normal weight (adults: BMI $<25 \mathrm{~kg} / \mathrm{m} 2$; children: BMI $<85^{\text {th }}$ percentile), overweight (adults: $25 \mathrm{~kg} / \mathrm{m} 2 \leq \mathrm{BMI}<30 \mathrm{~kg} / \mathrm{m} 2$; children: $85^{\text {th }}$ percentile $\leq \mathrm{BMI}<95^{\text {th }}$ percentile), and obese (adults: BMI $\geq 30 \mathrm{~kg} / \mathrm{m} 2$; children: BMI $\geq 95^{\text {th }}$ percentile).

\subsection{Statistical analysis}

NHANES uses a complex, multistage probability sampling design to represent a nationally civilian non-institutionalized U.S. population. Therefore, appropriate published sample weights from the CDC were applied to account for the differential probability of selection, non-response adjustment, and adjustment to independent population controls. The Taylor series linearization method was used for variance estimation to account for stratification and clustering, following NHANES Analytic Guidelines [44]. We calculated both the initial tin concentrations and the creatinine adjusted tin concentration in this study (Barr et al., 2005). The median and geometric mean of urinary tin concentrations according to population characteristics were computed for children and adults, respectively. We used analysis of variance (ANOVA) to compare differences of urinary tin concentrations (log transformed) among various categorical variables. We conducted linear regression analyses by including all the variables simultaneously in the model to detect independent effects of each variable. All statistical analyses were performed with SAS software (version 9.4; SAS Institute). P < 0.05 was considered statistically significant.

\section{Results and Discussion}

\subsection{Urinary levels of tin in U.S. adults}

A summary of the characteristics of the study population is provided in Table 1. Tin was detected in most urine samples analyzed as part of NHANES 2011-2012 and NHANES 2013-2014, with an overall detection rate of $87.05 \%$ in adults ( $=3,522$; Table 2) and $91.29 \%$ in children ( $\mathrm{N}=1,641$; Table 4$)$. A comparable detection frequency of tin of $89 \%$ has been reported for urine samples collected as part of the NHANES III and the NHANES 1988 to 1994 cycles (Paschal et al., 1998). A lower detection frequency of 62\% and 62\% has been reported in biomonitoring studies from the PR China (Feng et al., 2015) and the United Kingdom (Morton et al., 2014), respectively. It is unclear if these differences in the detection frequency reflect differences in the analytical method or are indicative of regional differences in tin exposure. Organotin compounds, including monobutyltin, dibutyltin, and tributyltin, were detected in 53\%, 81\%, 70\%, respectively, of blood samples collected from US adults in 1998 (Kannan et al., 1999); however, it is currently unknown if and to which extent organotin compounds contribute to total tin levels in the general U.S. population, as determined using ICP-MS. 
Median and geometric mean levels of urinary tin in the adult U.S. population were $0.42 \mu \mathrm{g} / \mathrm{L}$ (interquartile range [IQR], 0.21-0.92 $\mu \mathrm{g} / \mathrm{L}$ ) and $0.49 \mu \mathrm{g} / \mathrm{L}$ (standard error [SE], $0.02 \mu \mathrm{g} / \mathrm{L}$ ), respectively (Table 2). Comparable geometric mean tin levels were detected in biomonitoring studies from Belgium and Germany, with levels of $0.289 \mu \mathrm{g} / \mathrm{L}$ (range 0.26 to $0.32 \mu \mathrm{g} / \mathrm{L} ; \mathrm{N}=1,022$; collected 2010 to 2011) in adults from Belgium (Hoet et al., 2013) and $0.84 \mu \mathrm{g} / \mathrm{L}$ (range 0.06 to $204 \mu \mathrm{g} / \mathrm{L} ; \mathrm{N}=87$; collected in 2005) in adults from Germany (Heitland and Köster, 2006). The median urinary tin level was $0.33 \mu \mathrm{g} / \mathrm{L}$ in adults from the UK ( $\mathrm{N}=132$; samples collected before 2014) (Morton et al., 2014). Somewhat higher geometric mean tin levels of $0.99 \mu \mathrm{g} / \mathrm{L}(2.0 \mu \mathrm{g} / \mathrm{g}$ creatinine; $\mathrm{N}=37$; collected from 1999 to 2004) were reported for urine samples from Japanese women (Shimbo et al., 2007). Higher urinary tin levels were observed in earlier studies of the NHANES III (1988 to 1994) population, with geometric mean urinary tin level of $3.13 \mu \mathrm{g} / \mathrm{L}(2.84 \mu \mathrm{g} / \mathrm{g}$ creatinine; $\mathrm{N}=$ 496) (Paschal et al., 1998; Poddalgoda et al., 2016), and the general U.S. patient population (1997 to 1998), with median tin level of $2.7 \mu \mathrm{g} / \mathrm{L}(3.0 \mu \mathrm{g} / \mathrm{g}$ creatinine; $\mathrm{N}=1,809)$

(Komaromy-Hiller et al., 2000), most likely due to higher exposures to tin resulting from the more frequent consumption of food stored in unlacquered or partially lacquered tin cans (Poddalgoda et al., 2016).

Creatinine adjusted geometric mean levels of tin reported for adults in the NHANES 20112014 cycles were $0.56 \mu \mathrm{g} / \mathrm{g}$ creatinine. An earlier analysis of NHANES 2011-2012 data alone reported a slightly higher geometric mean value of $0.665 \mu \mathrm{g} / \mathrm{g}$ creatinine (95\% CI, 0.599 to $0.737 \mu \mathrm{g} / \mathrm{g}$ creatinine) (Poddalgoda et al., 2016). A comparable geometric mean level of tin of $0.51 \mu \mathrm{g} / \mathrm{g}$ creatinine (95\% CI, 0.49 to $0.53 \mu \mathrm{g} / \mathrm{g}$ creatinine) was reported for adults for samples collected from 2006 to 2007 as part of the National Nutrition and Health Study of France (Poddalgoda et al., 2016). Based on an analysis of several earlier human biomonitoring studies, Morton et al. noted that the $95^{\text {th }}$ percentiles of tin levels are comparable across studies from Europe and the U.S. and suggests that diet and environment have less of an effect on tin levels (Morton et al., 2014); however, a detailed analysis of demographic, socioeconomic and lifestyle factors associated with total tin levels has not been reported to date.

\subsection{Factors affecting urinary levels of tin in U.S. adults}

Urinary tin levels were significantly different between the three adult age groups, both for unadjusted and creatinine adjusted tin levels ( $\mathrm{P}<0.0001$ and $\mathrm{P}<0.0001$, respectively) and increased with age (Table 2). For example, the lowest median tin levels, adjusted by volume, were observed in the 20-39 year age group $(0.36 \mu \mathrm{g} / \mathrm{L}$; IQR, $0.16-0.80 \mu \mathrm{g} / \mathrm{L})$, whereas median tin levels were almost 2 -fold higher in the $\geq 60$ year age group $(0.60 \mu \mathrm{g} / \mathrm{L} ; \mathrm{IQR}$, $0.32-1.36 \mu \mathrm{g} / \mathrm{L}$ ). According to the linear regression analysis, urinary tin levels in the 40-59 ( $\beta$ coefficient $0.19, \mathrm{P}<0.0001$ ) and $\geq 60$ year age group ( $\beta$ coefficient $0.77, \mathrm{P}<0.0001$ ) were significantly different compared to the 20-39 year age group (Table 3 ). In an earlier study from Japan, urinary tin levels also increased with age in healthy adults from the Aichi prefecture (Hayashi et al., 1991). An increase in urinary tin levels with age has also been observed in participants of the 2006-2007 French National Survey on Nutrition and Health (Poddalgoda et al., 2016). 
Urinary tin levels, expressed as $\mu \mathrm{g} / \mathrm{L}$, were not significantly different between male and female U.S. adults ( $\mathrm{P}=0.40$; Table 2$)$. However, significantly higher creatinine adjusted tin levels were observed in female compared to male adults $(\mathrm{P}<0.0001)$. According to the linear regression analysis, urinary tin levels were significantly different between men and women ( $\beta$ coefficient $0.31, \mathrm{P}<0.0001$, Table 3 ). Earlier analyses of NHANES data (NHANES III, 1988 to 1994) revealed a negative correlation by sex, both for unadjusted and creatinine adjusted tin levels (Paschal et al., 1998). A small human biomonitoring study for Japan as well as the French National Survey on Nutrition and Health also observed higher urinary, creatinine-adjusted tin levels in female compared to male adults (Hayashi et al., 1991; Poddalgoda et al., 2016), whereas no significant effect of gender was observed in a study of adults from the United Kingdom (Morton et al., 2014). Because we observed significant differences in urinary tin levels by gender after adjusting for urinary creatinine levels in the linear regression analysis, it is possible that these differences are due to genderspecific differences in the uptake and/or elimination of tin compounds in men $v s$. women.

Significant differences in the urinary tin levels, expressed as $\mu \mathrm{g} / \mathrm{L}$, were observed depending on the reported race/ethnicity, with non-Hispanic blacks showing the highest levels of 0.74 $\mu \mathrm{g} / \mathrm{L}(\mathrm{P}=0.03$, Table 2). However, no significant differences in tin levels were observed for ethnicity/race after creatinine adjustment (Tables 2 and 3).

Income to poverty ratios were significantly associated with urinary tin levels, both adjusted by volume $(\mathrm{P}=0.049)$ and creatinine levels $(\mathrm{P}=0.03)$, with urinary tin levels decreasing with increasing household income (Table 2). According to the linear regression analysis, tin levels in U.S. adults in the low-income group (PIR $\leq 1.30$ ) were significantly different from individuals with the high-income group ( $\mathrm{PIR}>3.50 ; \beta$ coefficient $-0.18, \mathrm{P}=0.02$; Table 3 ).

Physical activity was significantly associated with tin levels in U.S. adults when adjusting for volume ( $\mathrm{P}=0.03)$ and creatinine $(\mathrm{P}=0.02)$, with adults with higher physical activity eliminating lower levels of tin in their urine compared to those with less physical activity (Table 2). In the multivariate analysis, urinary tin levels in the $>1200$ MET-min/week group were significantly different from the $<600 \mathrm{MET}-\mathrm{min} /$ week group $(\beta$ coefficient $-0.17, \mathrm{P}=$ $0.01)$.

Alcohol consumption was associated with tin levels adjusted for both volume $(\mathrm{P}=0.02)$ and creatinine $(P=0.001)$ and appeared to be lower in individuals consuming alcohol than individuals who did not consume alcohol (Table 2). This difference did not reach statistical significance in the linear regression analysis.

BMI was associated with urinary tin levels adjusted for creatinine $(\mathrm{P}=0.01)$; however, no significant differences were observed in the linear regression analysis. Other factors, such as education and smoking, were not significantly associated with urinary tin levels in the adult U.S. population (Tables 2 and 3). In contrast, smoking increased urinary tin levels, but this difference did not reach statistical significance in a study performed from 1986 to 1988 in the Aichi prefecture in Japan (Hayashi et al., 1991). In a study of an adult population from Belgium, cigarette smoking was associated with significantly higher urinary tin levels 
compared to non-smoking adults ( $\mathrm{p}<0.0001)$; however, it is unclear if this difference was due to smoking or differences in creatinine levels in this study population (Hoet et al., 2013).

Consumption of food, in particular canned food and beverages, is generally assumed to be a major source of dietary exposure to tin. However, the general U.S. population consumes canned foods, including canned beverages, only with a frequency of $41 \%$, based on an analysis of NHANES 2003-2008 data (Hartle et al., 2016). Moreover, this earlier analysis revealed trends in the consumption of canned foods that are typically inconsistent with the associations observed in the present analysis. For example, consumption of canned foods was higher in men, not women; higher compared to other races in non-Hispanic Whites, not in non-Hispanic Blacks; and lower in the lowest, not the highest income group. Further studies are therefore warranted to better characterize sources of human exposure to tin and to explain the differences in urinary tin levels, and by extension the internal tin dose, observed in the NHANES 2011-2014 population.

\subsection{Factors affecting urinary levels of tin in U.S. children}

For children age 6 to 19 years old, median and geometric mean levels of urinary tin were $0.60 \mu \mathrm{g} / \mathrm{L}$ (IQR, 0.27-1.58 $\mu \mathrm{g} / \mathrm{L}$ ) and $0.66 \mu \mathrm{g} / \mathrm{L}$ (SE, $0.04 \mu \mathrm{g} / \mathrm{L}$ ), respectively (Table 4). In comparison, children from a German study had a lower geometric mean levels of $0.35 \mu \mathrm{g} / \mathrm{L}$ (range 0.03 to $11.7 \mu \mathrm{g} / \mathrm{L} ; \mathrm{N}=72$; collected in 2005) (Heitland and Köster, 2006). As described below, total urinary tin levels were associated with age, race/ethnicity and household income, but not gender or BMI in U.S. children (Tables 4 and 5).

Urinary tin levels were significantly different between 6-11 and 12-19 year old children, both for unadjusted and creatinine adjusted tin levels $(\mathrm{P}<0.0001$ and $\mathrm{P}<0.0001$, respectively; Table 4). For example, median, volume-adjusted tin levels in children (0.94 $\mu \mathrm{g} / \mathrm{L}$; IQR, 0.43-2.48 $\mu \mathrm{g} / \mathrm{L})$ were 2-fold higher than in adolescents $(0.43 \mu \mathrm{g} / \mathrm{L}$; IQR, 0.22 $1.01 \mu \mathrm{g} / \mathrm{L})$. Urinary tin levels were also significantly different according to the linear regression analysis ( $\beta$ coefficient $-1.08, \mathrm{P}<0.0001$; Table 5 ). Similarly, an earlier analysis of NHANES 2011-2012 data suggests that geometric mean urinary tin levels are 3-fold higher in 6-11 compared to the 12-19 year old children (Poddalgoda et al., 2016).

As with U.S. adults, significant differences in the urinary tin levels, expressed as $\mu \mathrm{g} / \mathrm{L}$, were observed depending on the reported race/ethnicity $(P=0.001$; Table 4$)$. Non-Hispanic black children had 2-fold higher median levels (1.16 $\mu \mathrm{g} / \mathrm{L}$; IQR, 0.46-2.68 $\mu \mathrm{g} / \mathrm{L})$ compared to non-Hispanic white children $(0.48 \mu \mathrm{g} / \mathrm{L} ; \mathrm{IQR}, 0.24-1.24 \mu \mathrm{g} / \mathrm{L})$. In the linear regression analysis, urinary tin levels differed significantly between non-Hispanic black and nonHispanic white children ( $\beta$ coefficient $0.30, \mathrm{P}<0.01$; Table 5 ).

Household income was significantly associated with urinary tin levels, both adjusted by volume $(P=0.02)$ and creatinine levels $(P=0.03$; Table 4$)$. As with U.S. adults, urinary tin levels decreased with increasing household income. According to the linear regression analysis, tin levels in U.S. children in the group with lowest household income (PIR < 1.30) were significantly different from children in both the middle (PIR 1.30-3.50; $\beta$ coefficient $-0.20, \mathrm{P}<0.047$ ) and high income group (PIR > 3.50; $\beta$ coefficient $-0.42, \mathrm{P}<0.0001$; Table 
5). Interestingly, an earlier analysis of the consumption of canned foods did not reveal an association between the mean daily canned food consumption and household income [50].

Several factors may contribute to the elevated levels of tin observed in children compared to adolescents, but also in adults (see Section 3.1) (EPA, 2007): Exposure of children to chemicals is typically higher compared to adults because children have a higher food intake compared to adults, are exposed to tin via ingestion of household dust, or have more (dermal) contact with products containing tin. Indeed, several studies estimate a higher dietary intake for tin in children compared to adults. Moreover, an analysis of data from earlier NHANES cycles suggests that the consumption of canned food was highest in young U.S. adults (Hartle et al., 2016). While these observations may explain the comparatively high tin levels in children, several studies from Japan and Korea did not observe an association between consumption of canned food and urinary tin levels (Hayashi et al., 1991; Shimbo et al., 2007; Shimbo et al., 2013; Yang et al., 2015). While likely a minor source of exposure, tin compounds, including organotin compounds, are present in household dust (Fromme et al., 2005; Turner and Simmonds, 2006) and can represent a source of tin exposure in children (Barbieri et al., 2014). Exposures via the drinking water or air are also unlikely to make significant contribution to the exposure of children to tin (Schroeder et al., 1964; WHO, n.d.-c). Finally, we can also not discount the possibility that difference in the disposition of tin in children $v s$. adults contribute to higher urinary levels of tin substitutes in children.

\section{Conclusions}

Using data from a nationally representative health survey, the present analysis confirms findings from earlier human biomonitoring studies that the exposure of the general U.S. population to tin compounds is almost ubiquitous. Importantly, this study identifies demographic, socioeconomic and lifestyle factors associated with higher exposures to tin compounds in the general U.S. population, including age, gender, household income and physical activity in U.S. adults and age, race/ethnicity and household income in U.S. children. Like most other biomonitoring studies, this study reported only total urinary levels using ICP-MS and did not distinguish between organic and inorganic forms of tin. Because emerging evidence from epidemiological studies suggests that environmental exposures to tin are linked to adverse health outcomes in humans, future studies are needed to better characterize modifiable factors that can be used to reduce human exposures to total tin and different forms of tin.

\section{Acknowledgments}

Funding sources

This work was supported by the National Institute of Environmental Health Sciences/National Institutes of Health [grant number P30 ES005605]. The findings and conclusions in this manuscript are those of the authors and do not necessarily represent the views of the National Institute of Environmental Health Sciences/National Institutes of Health. 


\section{References}

Airaksinen R, Rantakokko P, Turunen AW, Vartiainen T, Vuorinen PJ, Lappalainen A, Vihervuori A, Mannio J, Hallikainen A. Organotin intake through fish consumption in Finland. Environ. Res. 2010; 110:544-547. [PubMed: 20573344]

ATSDR. [Accessed on April 28, 2018] Toxicological Profile for Tin. n.d. Available at https:// www.atsdr.cdc.gov/toxprofiles/TP.asp?id=543\&tid=98

Barbieri E, Fontúrbel FE, Herbas C, Barbieri FL, Gardon J. Indoor metallic pollution and children exposure in a mining city. Sci. Total Environ. 2014; 487:13-19. [PubMed: 24762646]

Barr DB, Wilder LC, Caudill SP, Gonzalez AJ, Needham LL, Pirkle JL. Urinary creatinine concentrations in the U.S. population: implications for urinary biologic monitoring measurements Environ. Health Perspect. 2005; 113:192-200. [PubMed: 15687057]

Benoy CJ, Hooper PA, Schneider R. The toxicity of tin in canned fruit juices and solid foods. Food Cosmet. Toxicol. 1971; 9:645-656. [PubMed: 5157556]

Blunden S, Wallace T. Tin in canned food: A review and understanding of occurrence and effect. Food Chem. Toxicol. 2003; 41:1651-1662. [PubMed: 14563390]

Boogaard PJ, Boisset M, Blunden S, Davies S, Ong TJ, Taverne J-P. Comparative assessment of gastrointestinal irritant potency in man of tin(II) chloride and tin migrated from packaging. Food Chem. Toxicol. 2003; 41:1663-1670. [PubMed: 14563391]

Calloway D, McMullen J. Fecal excretion of iron and tin by men fed stored canned foods. Am. J. Clin. Nutr. 1966; 18:1-6. [PubMed: 5900423]

Carlin JF, Jr. U.S. Geological Survey (USGS). [Accessed April 28, 2018] Mineral Commodity Summaries 2004. n.d. Available at https://minerals.usgs.gov/minerals/pubs/mcs/2004/mcs2004.pdf

CDC, n.d.-a. Centers for Disease Control and Prevention (CDC). [Accessed on April 28, 2018] National Health and Nutrition Examination Survey. Available at https://wwwn.cdc.gov/nchs/data/ nhanes/2013-2014/labmethods/UM_UMS_UTAS_UTASS_H_MET.pdf

CDC, n.d.-b. Centers for Disease Control and Prevention (CDC). [Accessed on April 28, 2018] National Health and Nutrition Examination Survey: Analytic Guidelines. Available at https:// wwwn.cdc.gov/nchs/nhanes/analyticguidelines.aspx

Choi M, Moon H-B, Choi H-G. Intake and potential health risk of butyltin compounds from seafood consumption in korea. Arch. Environ. Contam. Toxicol. 2012; 62:333-340. [PubMed: 21674223]

ENVISA. [Accessed on April 28, 2018] EU bans certain organotin compounds. n.d. http:// www.speciation.net/News/EU-bans-certain-organotin-compounds-; /2009/06/05/4298.html

EPA. A decade of children's environmental health research: Highlights from EPA's science to achieve results program. 2007.

FDA. [Accessed on April 28, 2018] Title 21 Food and Drugs. Part 582-Substances generally recognized as safe. n.d. Available at https://www.ecfr.gov/cgi-bin/text-idx? $\mathrm{SID}=\mathrm{b} 102 \mathrm{e} 899 \mathrm{f} 1 \mathrm{~d} 4744 \mathrm{~b} 797777 \mathrm{~d} 848 \mathrm{c} 10 \mathrm{ca} \& \mathrm{mc}=$ true $\&$ node $=\mathrm{pt} 21.6 .582 \& \mathrm{rgn}=\mathrm{div} 5$

Feng W, Cui X, Liu B, Liu C, Xiao Y, Lu W, Guo H, He M, Zhang X, Yuan J, Chen W, Wu T. Association of urinary metal profiles with altered glucose levels and diabetes risk: a populationbased study in China. PLoS One. 2015; 10:e0123742. [PubMed: 25874871]

Filipkowska A, Złoch I, Wawrzyniak-Wydrowska B, Kowalewska G. Organotins in fish muscle and liver from the Polish coast of the Baltic Sea: Is the total ban successful? Marine Poll. Bull. 2016; 111:493-499.

Fromme H, Mattulat A, Lahrz T, Rüden H. Occurrence of organotin compounds in house dust in Berlin (Germany). Chemosphere. 2005; 58:1377-1383. [PubMed: 15686755]

Glassmeyer ST, Furlong ET, Kolpin DW, Batt AL, Benson R, Boone JS, Conerly O, Donohue MJ, King DN, Kostich MS, Mash HE, Pfaller SL, Schenck KM, Simmons JE, Varughese EA, Vesper SJ, Villegas EN, Wilson VS. Nationwide reconnaissance of contaminants of emerging concern in source and treated drinking waters of the United States. Sci. Total Environ. 2017; 581-582:909_ 922.

Greig JB, Pennington JA. [Accessed on April 28, 2018] WHO Food Additives Series 46: Tin (addendum). n.d. Available at http://www.inchem.org/documents/jecfa/jecmono/ v46je12.htm\#_46123380 
Grün F. Obesogens. Curr. Opin. Endocrinol. Diabetes Obes. 2010; 17:453-459. [PubMed: 20689419]

Guérin T, Sirot V, Volatier JL, Leblanc JC. Organotin levels in seafood and its implications for health risk in high-seafood consumers. Sci. Total Environ. 2007; 388:66-77. [PubMed: 17889928]

Hartle JC, Navas-Acien A, Lawrence RS. The consumption of canned food and beverages and urinary Bisphenol A concentrations in NHANES 2003-2008. Environ. Res. 2016; 150:375-382. [PubMed: 27362993]

Hayashi R, Shima S, Hayakawa K. A study on urinary tin in healthy adults; Relationship between the concentration of urinary tin and life style. Jpn. J. Hyg. 1991; 46:898-904.

Heindel JJ, Blumberg B, Cave M, Machtinger R, Mantovani A, Mendez MA, Nadal A, Palanza P, Panzica G, Sargis R, Vandenberg LN, vom Saal F. Metabolism disrupting chemicals and metabolic disorders. Reprod. Toxicol. 2017; 68:3-33. [PubMed: 27760374]

Heitland P, Köster HD. Biomonitoring of 30 trace elements in urine of children and adults by ICP-MS. Clin. Chim. Acta. 2006; 365:310-318. [PubMed: 16248993]

Hiles RA. Absorption, distribution and excretion of inorganic tin in rats. Toxicol. Appl. Pharmacol. 1974; 27:366-379. [PubMed: 4850377]

Hoet P, Jacquerye C, Deumer G, Lison D, Haufroid V. Reference values and upper reference limits for 26 trace elements in the urine of adults living in Belgium. Clin. Chem. Lab. Med. 2013; 51:839849. [PubMed: 23314559]

IMO. [Accessed on April 28, 2018] International convention on the control of harmful anti-fouling systems on ships. n.d. Available at http://www.imo.org/en/About/Conventions/listofconventions/ pages/international-convention-on-the-control-of-harmful-anti-fouling-systems-on-ships-(afs).aspx

IPCS. [Accessed on April 28, 2018] Tin. n.d. Available at http://www.inchem.org/documents/jecfa/ jecmono/v024je13.htm

ITRI. [Accessed on April 28, 2018] Thirteenth annual survey of tin use. News release, Frogmore, United Kingdom. 2017. Available at https://www.itri.co.uk/market-analysis/news-2/itri-surveyshows-recovery-in-tin-use-in-2017

Johnson CL, Paulose-Ram R, Ogden CL, Carroll MD, Kruszon-Moran D, Dohrmann SM, Curtin LR. National Health and Nutrition Examination Survey: Analytic Guidelines, 1999-2010. Vital Health Stat. 2013; 2:1-24.

Johnson MA, Greger JL. Effects of dietary tin on tin and calcium metabolism of adult males. Am. J. Clin. Nutr. 1982; 35:655-660. [PubMed: 7072618]

Julião LMQC, Melo DR, Sousa WO, Santos MS, Fernandes PC, Godoy MLDP. Exposure of workers in a mineral processing industry in Brazil. Radiat. Prot. Dosim. 2007; 125:513-515.

Kannan K, Senthilkumar K, Giesy JP. Occurrence of butyltin compounds in human blood. Environ. Sci. Technol. 1999; 33:1776-1779.

Komaromy-Hiller G, Ash KO, Costa R, Howerton K. Comparison of representative ranges based on U.S. patient population and literature reference intervals for urinary trace elements. Clin. Chim. Acta. 2000; 296:71-90. [PubMed: 10807972]

Liu B, Feng W, Wang J, Li Y, Han X, Hu H, Guo H, Zhang X, He M. Association of urinary metals levels with type 2 diabetes risk in coke oven workers. Environ. Pollut. 2016; 210:1-8. [PubMed: 26689646]

Liu B, Lehmler H-J, Sun Y, Xu G, Liu Y, Zong G, Sun Q, Hu FB, Wallace RB, Bao W. Bisphenol A (BPA), BPA substitutes, and obesity in U.S. adults. Lancet Planet. Health. 2017; 1:e114-e122. [PubMed: 29308453]

Mance G, O'Donnell AR, Campbell JA, Gunn AM. Proposed Environmental Quality Standards for List II Substances in Water : Inorganic Tin. Marlow, Bucks: Water Research Centre; 1988.

Morton J, Tan E, Leese E, Cocker J. Determination of 61 elements in urine samples collected from a non-occupationally exposed UK adult population. Toxicol. Lett. 2014; 231:179-193. [PubMed: 25151427]

Ostrakhovitch EA. Tin. In: Nordberg GF, Fowler BA, Nordberg M, editorsHandbook on the Toxicology of Metals. 4. Academic Press; 2014. 1241-1285.

Paschal DC, Ting BG, Morrow JC, Pirkle JL, Jackson RJ, Sampson EJ, Miller DT, Caldwell KL. Trace metals in urine of United States residents: Reference range concentrations. Environ. Res. 1998; 76:53-59. [PubMed: 9466897] 
Poddalgoda D, Macey K, Jayawardene I, Krishnan K. Derivation of biomonitoring equivalent for inorganic tin for interpreting population-level urinary biomonitoring data. Regul. Toxicol. Pharmacol. 2016; 81:430-436. [PubMed: 27693705]

Rantakokko P, Main KM, Wohlfart-Veje C, Kiviranta H, Airaksinen R, Vartiainen T, Skakkebaek NE, Toppari J, Virtanen HE. Association of placenta organotin concentrations with congenital cryptorchidism and reproductive hormone levels in 280 newborn boys from Denmark and Finland. Hum. Reprod. 2013; 28:1647-1660. [PubMed: 23520400]

Rantakokko P, Main KM, Wohlfart-Veje C, Kiviranta H, Airaksinen R, Vartiainen T, Skakkebaek NE, Toppari J, Virtanen HE. Association of placenta organotin concentrations with growth and ponderal index in 110 newborn boys from Finland during the first 18 months of life: a cohort study. Environ. Health. 2014; 13:45. [PubMed: 24899383]

Schroeder HA, Balassa JJ, Tipton IH. Abnormal trace metals in man: Tin. J. Chronic. Dis. 1964; 17:483-502. [PubMed: 14170739]

Shimbo S, Matsuda-Inoguchi N, Watanabe T, Sakurai K, Date C, Nishimura A, Nakatsuka H, Saito H, Arisawa K, Ikeda M. Dietary intake of tin in Japan, and the effects on intake of canned food and beverage consumption. Food Addit. Contam. 2007; 24:535-545. [PubMed: 17487665]

Shimbo S, Watanabe T, Nakatsuka H, Yaginuma-Sakurai K, Ikeda M. Dietary tin intake and association with canned food consumption in Japanese preschool children. Environ. Health Prev. Med. 2013; 18:230-236. [PubMed: 23108579]

Sousa ACA, Coelho SD, Pastorinho MR, Taborda-Barata L, Nogueira AJA, Isobe T, Kunisue T, Takahashi S, Tanabe S. Levels of TBT and other selected organotin compounds in duplicate diet samples. Sci. Total Environ. 2017; 574:19-23. [PubMed: 27621089]

Survey USG. U.S. Geological Survey (USGS). Commodity Statistics and Information. American Metal Market. 2010:118.

Turner A, Simmonds L. Elemental concentrations and metal bioaccessibility in UK household dust. Sci. Total Environ. 2006; 371:74-81. [PubMed: 16989894]

WHO. [Accessed on April 28, 2018] Trace elements in human nutrition and health. n.d.-a. Available at http://www.who.int/nutrition/publications/micronutrients/9241561734/en/

WHO, n.d.-b. World Health Organization (WHO). [Accessed on April 28, 2018] Global Physical Activity Questionnaire (GPAQ) analysis guide. Available at www.who.int/chp/steps/resources/ GPAQ_Analysis_Guide.pdf

WHO, n.d.-c. World Health Organization (WHO). [Accessed on April 28, 2018.1] Inorganic tin in drinking-water. Available at http://www.who.int/water_sanitation_health/dwq/chemicals/tin.pdf

Winship KA. Toxicity of tin and its compounds. Adverse Drug React. Acute Poisoning Rev. 1988; 7:19-38. [PubMed: 3291572]

Yang HR, Kim ES, Ko YS, Jung K, Kim JH, Watanabe T, Nakatsuka H, Moon CS, Shimbo S, Ikeda M. Food intake survey of kindergarten children in Korea: Part 2 increased dietary intake of tin possibly associated with canned foods. Environ. Health Prev. Med. 2015; 20:302-306. [PubMed: 25995117]

Zuo Z, Chen S, Wu T, Zhang J, Su Y, Chen Y, Wang C. Tributyltin causes obesity and hepatic steatosis in male mice. Environ. Toxicol. 2011; 26:79-85. [PubMed: 19760618] 


\section{Highlights}

- $\quad$ Urinary levels of tin were analyzed in U.S. adults and children

- $\quad$ Exposure of the general U.S. population to tin is almost ubiquitous

- $\quad$ Age is an important factor associated with urinary tin levels

- Tin levels are associated with gender, race, income and/or physical activity 


\section{站 \\ }

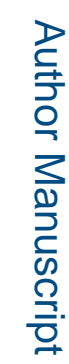

로을

$\frac{5}{\frac{0}{0}}$

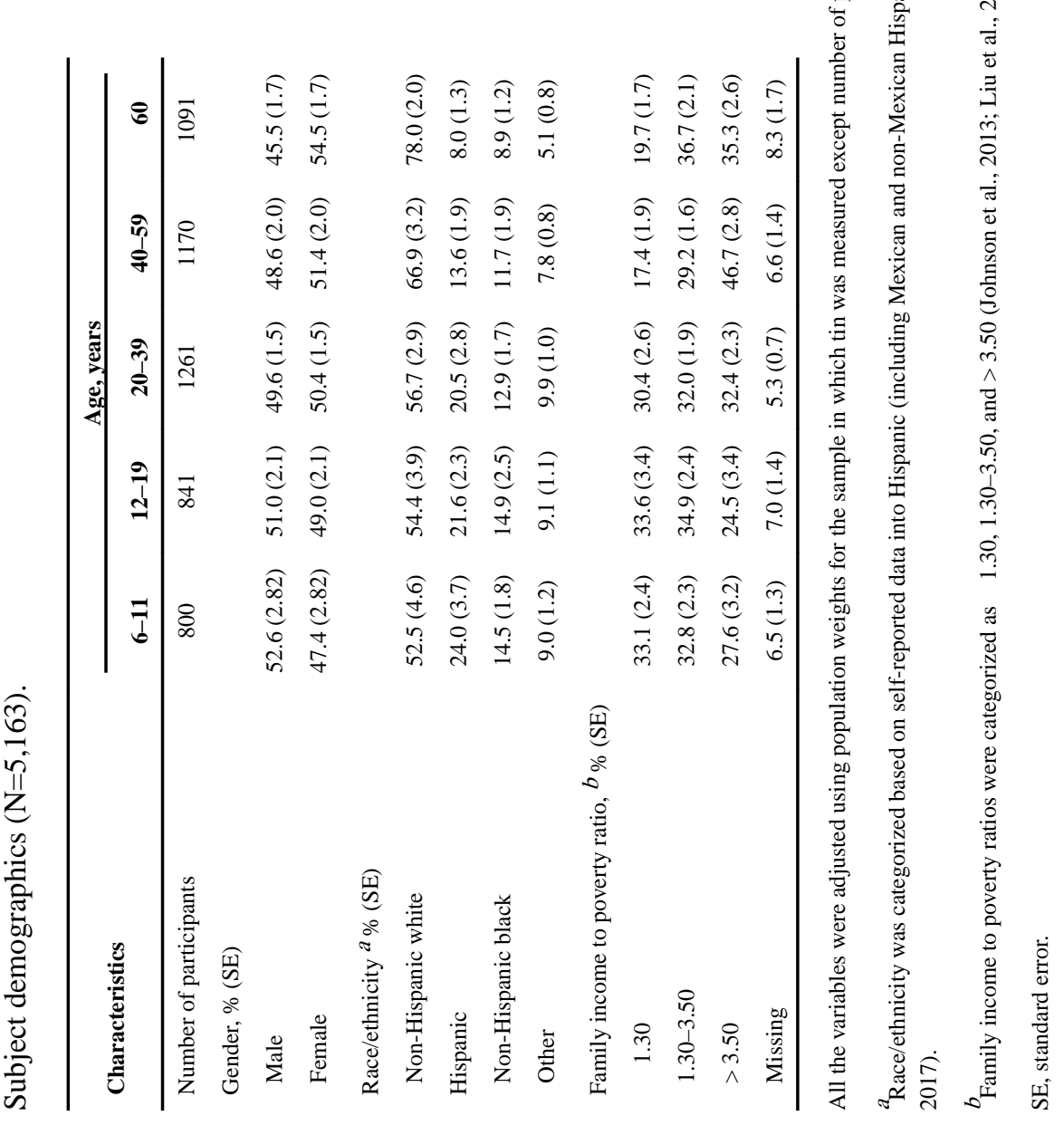

Environ Pollut. Author manuscript; available in PMC 2019 September 01. 


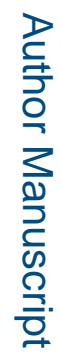

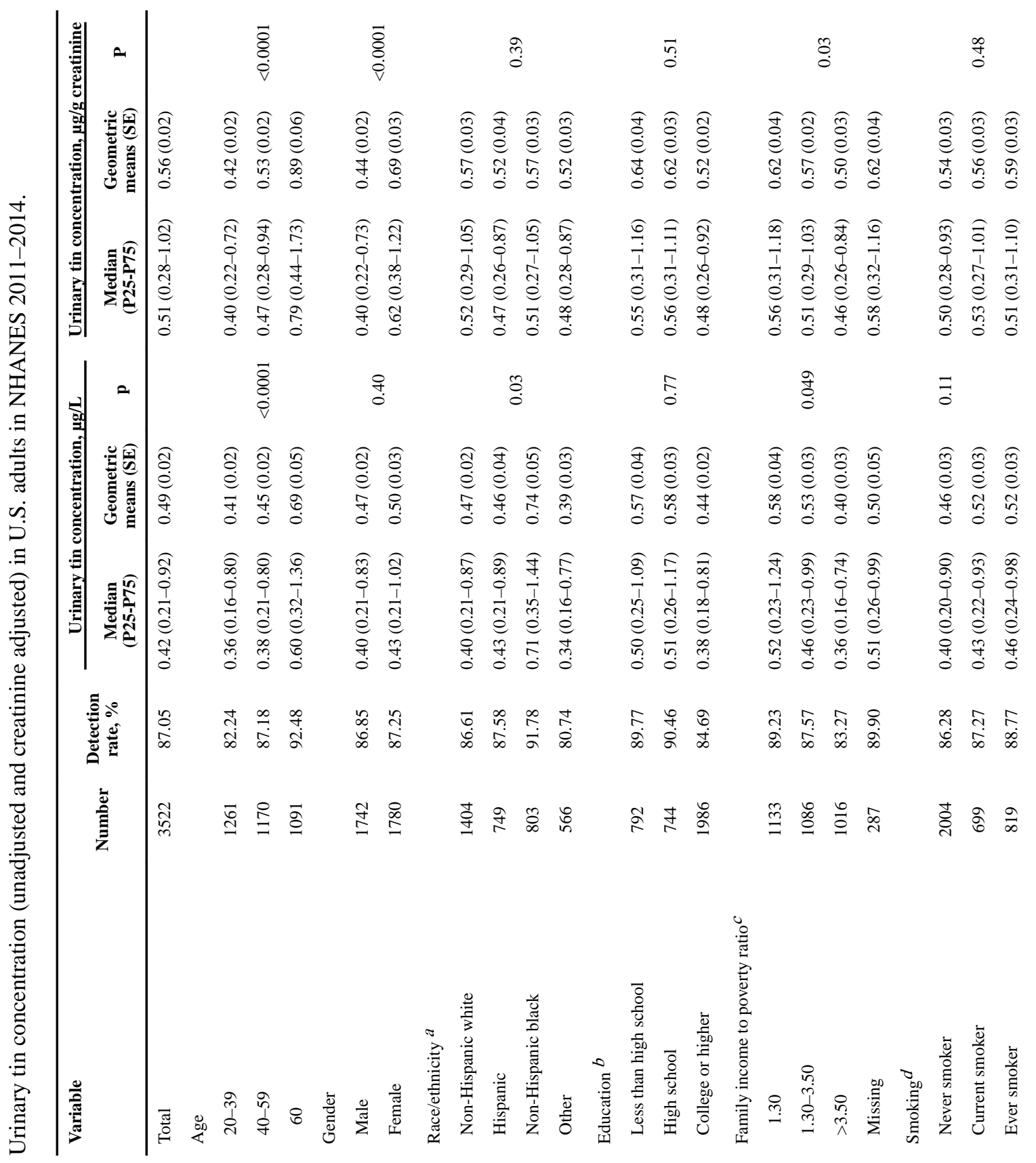




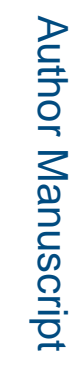

로을

$$
\text { }
$$

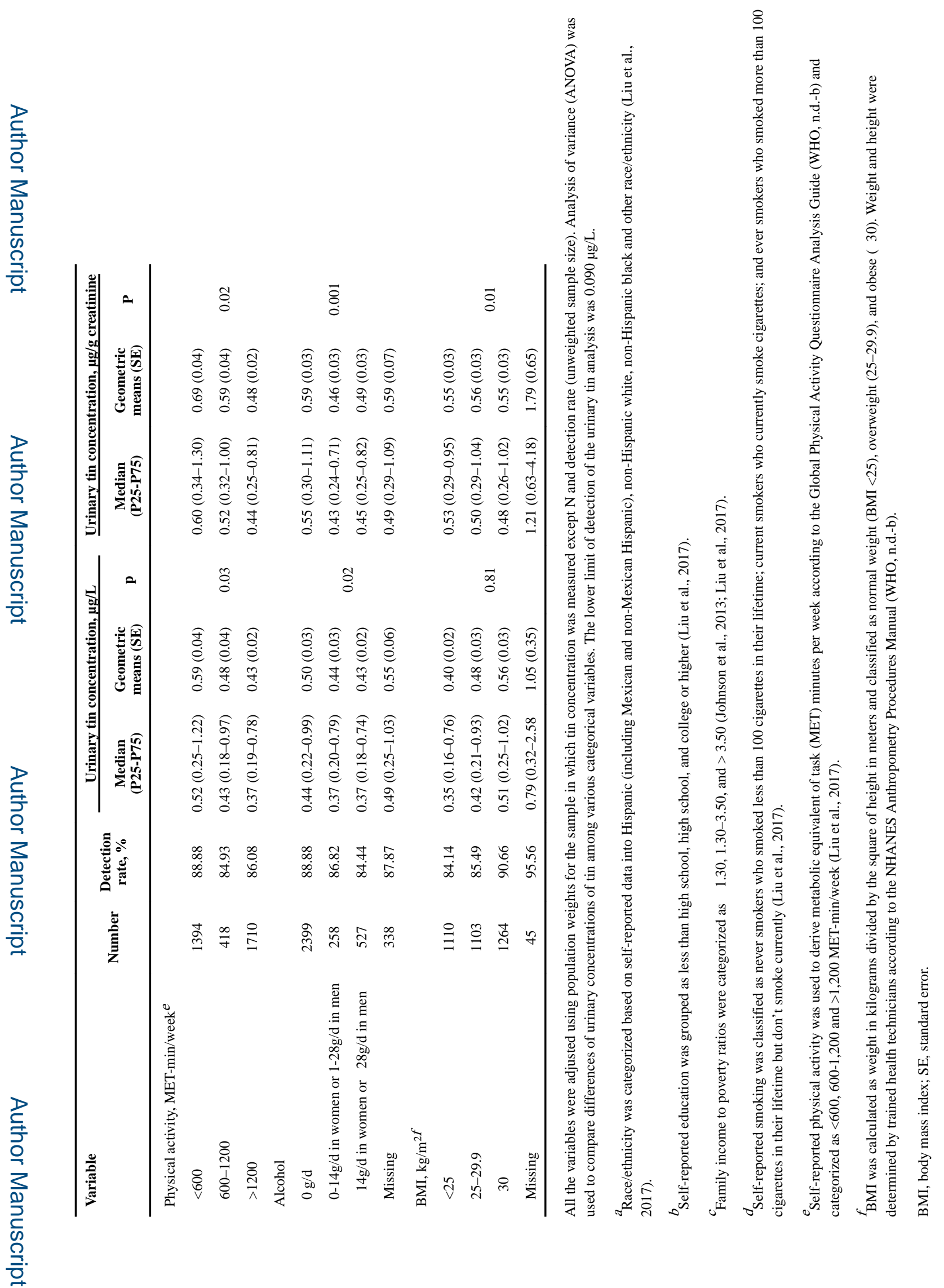

Environ Pollut. Author manuscript; available in PMC 2019 September 01. 
Table 3

Association of demographic and lifestyle factors in adults ( $\mathrm{N}=3,522)$ from NHANES 2011-2014 with urinary tin concentrations (creatinine was adjusted in the model).

\begin{tabular}{|c|c|c|}
\hline \multirow{2}{*}{ Variables } & \multicolumn{2}{|c|}{ Urinary tin concentrations } \\
\hline & $\beta$ coefficient & $\mathbf{P}$ \\
\hline \multicolumn{3}{|l|}{ Age } \\
\hline $20-39$ & [ref] & \\
\hline $40-59$ & 0.19 & $<0.0001$ \\
\hline 260 & 0.77 & $<0.0001$ \\
\hline \multicolumn{3}{|l|}{ Gender } \\
\hline Male & [ref] & \\
\hline Female & 0.31 & $<0.0001$ \\
\hline \multicolumn{3}{|l|}{ Race/ethnicity ${ }^{a}$} \\
\hline Non-Hispanic white & [ref] & \\
\hline Hispanic & -0.05 & 0.49 \\
\hline Non-Hispanic black & 0.09 & 0.13 \\
\hline Other & -0.07 & 0.25 \\
\hline \multicolumn{3}{|l|}{ Education $b$} \\
\hline Less than high school & [ref] & \\
\hline High school & 0.02 & 0.70 \\
\hline College or higher & -0.11 & 0.09 \\
\hline \multicolumn{3}{|l|}{ Family income to poverty ratioc } \\
\hline$\leq .30$ & [ref] & \\
\hline $1.30-3.50$ & -0.09 & 0.055 \\
\hline$>3.50$ & -0.18 & 0.02 \\
\hline Missing & -0.09 & 0.26 \\
\hline \multicolumn{3}{|l|}{ Smokingd } \\
\hline Never smoker & [ref] & \\
\hline Current smoker & 0.05 & 0.36 \\
\hline Ever smoker & -0.03 & 0.68 \\
\hline \multicolumn{3}{|l|}{ Physical activity, MET-min/weeke } \\
\hline$<600$ & [ref] & \\
\hline $600-1200$ & -0.10 & 0.13 \\
\hline$>1200$ & -0.17 & 0.01 \\
\hline \multicolumn{3}{|l|}{ Alcohol } \\
\hline $0 \mathrm{~g} / \mathrm{d}$ & [ref] & \\
\hline $0-14 \mathrm{~g} / \mathrm{d}$ in women or $1-28 \mathrm{~g} / \mathrm{d}$ in men & -0.13 & 0.11 \\
\hline$\geq 14 \mathrm{~g} / \mathrm{d}$ in women or $228 \mathrm{~g} / \mathrm{d}$ in men & -0.05 & 0.43 \\
\hline Missing & -0.07 & 0.33 \\
\hline \multicolumn{3}{|l|}{ BMI, $\mathrm{kg} / \mathrm{m}^{2 f}$} \\
\hline$<25$ & [ref] & \\
\hline $25-29.9$ & -0.01 & 0.88 \\
\hline
\end{tabular}




\begin{tabular}{lcc}
\hline \multirow{2}{*}{ Variables } & \multicolumn{2}{c}{ Urinary tin concentrations } \\
\cline { 2 - 3 } & $\beta$ coefficient & $\mathbf{P}$ \\
\hline$\geq 30$ & -0.04 & 0.44 \\
Missing & 0.82 & 0.02 \\
\hline
\end{tabular}

${ }^{a}$ Race/ethnicity was categorized based on self-reported data into Hispanic (including Mexican and non-Mexican Hispanic), non-Hispanic white, non-Hispanic black and other race/ethnicity (Liu et al., 2017).

$b_{\text {Self-rt }}$

Self-reported education was grouped as less than high school, high school, and college or higher (Liu et al., 2017).

${ }^{c}$ Family income to poverty ratios were categorized as $\leq 1.30,1.30-3.50$, and $>3.50$ (Johnson et al., 2013; Liu et al., 2017)

$d_{\text {Self }}$

feported smoking was classified as never smokers who smoked less than 100 cigarettes in their lifetime; current smokers who currently smoke cigarettes; and ever smokers who smoked more than 100 cigarettes in their lifetime but don't smoke currently (Liu et al., 2017).

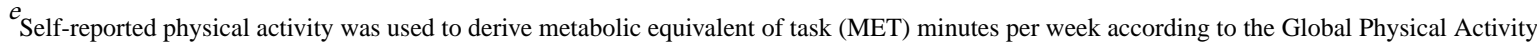
Questionnaire Analysis Guide (WHO, n.d.-b) and categorized as <600, 600-1,200 and >1,200 MET-min/week (Liu et al., 2017).

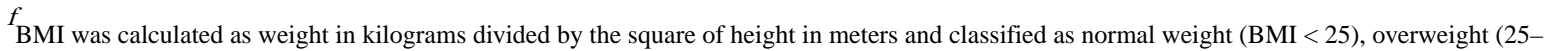
29.9), and obese ( 230 ). Weight and height were determined by trained health technicians according to the NHANES Anthropometry Procedures Manual (WHO, n.d.-b).

BMI, body mass index. 


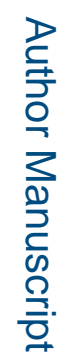

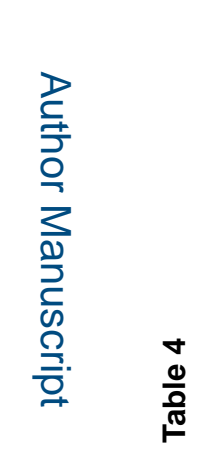

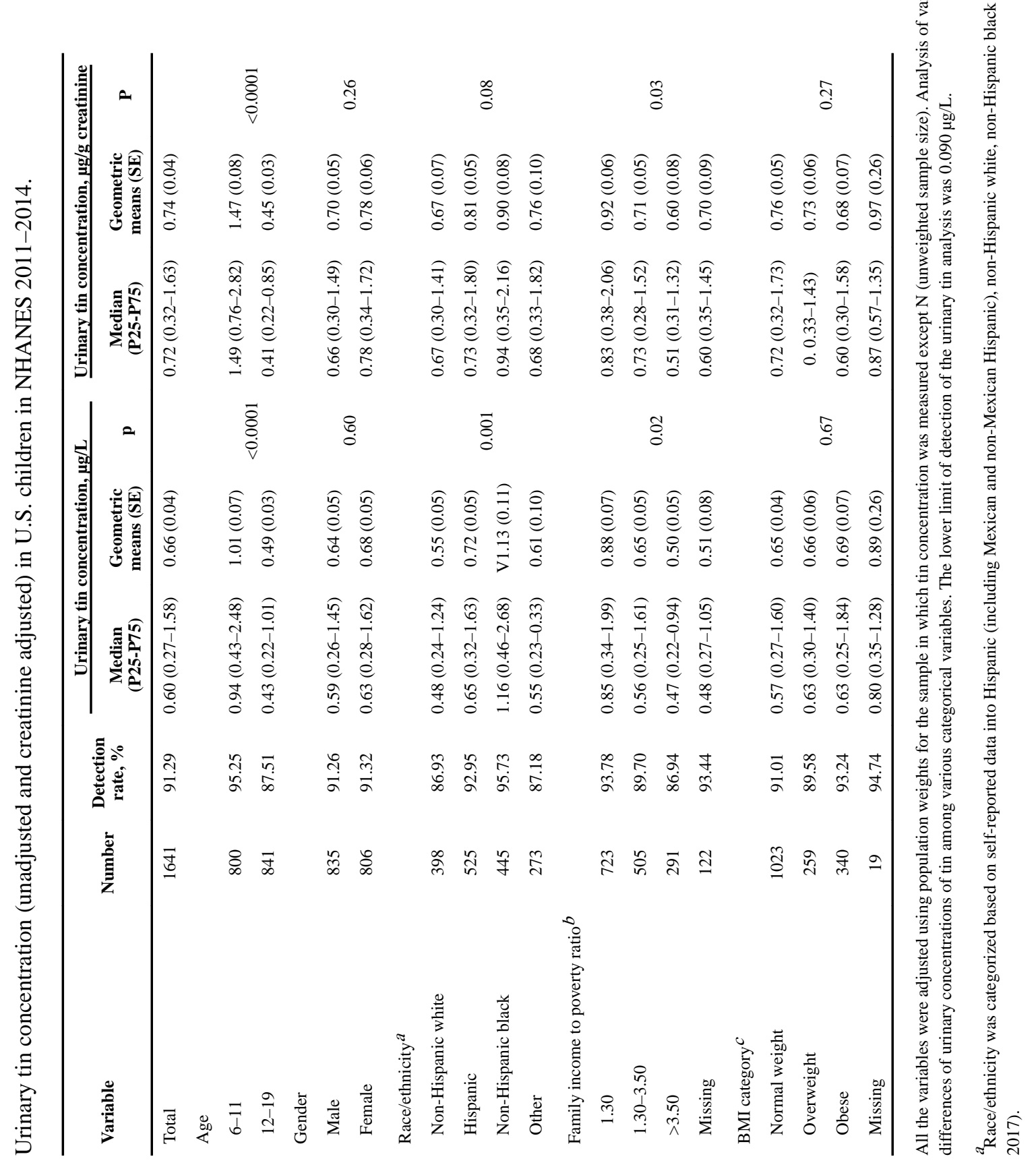

Environ Pollut. Author manuscript; available in PMC 2019 September 01. 


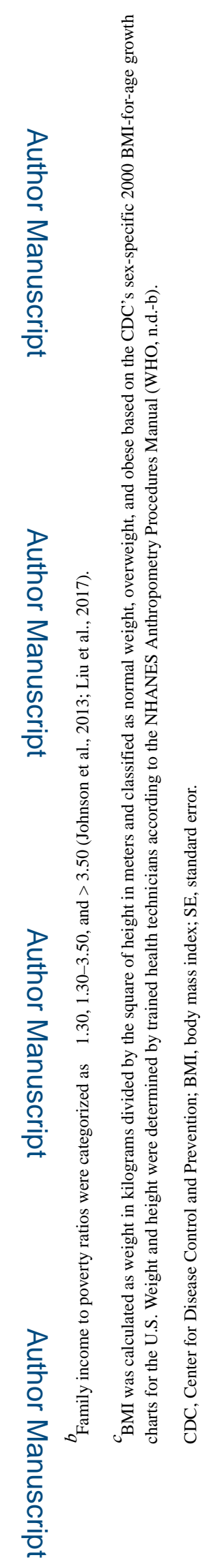


Table 5

Association of demographic factors in children ( $\mathrm{N}=1,641)$ from NHANES 2011-2014 with urinary tin concentrations (creatinine was adjusted in the model).

\begin{tabular}{|c|c|c|}
\hline \multirow{2}{*}{ Variables } & \multicolumn{2}{|c|}{ Urinary tin concentrations } \\
\hline & $\beta$ coefficient & $\mathbf{P}$ \\
\hline \multicolumn{3}{|l|}{ Age } \\
\hline $6-11$ & [ref] & \\
\hline $12-19$ & -1.08 & $<0.0001$ \\
\hline \multicolumn{3}{|l|}{ Gender } \\
\hline Male & [ref] & \\
\hline Female & 0.09 & 0.30 \\
\hline \multicolumn{3}{|l|}{ Race/ethnicity ${ }^{a}$} \\
\hline Non-Hispanic white & [ref] & \\
\hline Hispanic & 0.09 & 0.26 \\
\hline Non-Hispanic black & 0.30 & 0.01 \\
\hline Other & 0.08 & 0.65 \\
\hline \multicolumn{3}{|c|}{ Family income to poverty ratio $b$} \\
\hline$\unlhd .30$ & [ref] & \\
\hline $1.30-3.50$ & -0.20 & 0.047 \\
\hline$>3.50$ & -0.42 & $<0.0001$ \\
\hline Missing & -0.32 & 0.01 \\
\hline \multicolumn{3}{|l|}{ BMI, $\mathrm{kg} / \mathrm{m}^{2 \mathcal{C}}$} \\
\hline$<25$ & [ref] & \\
\hline $25-29.9$ & -0.07 & 0.31 \\
\hline$\geq 30$ & -0.11 & 0.27 \\
\hline Missing & 0.50 & 0.07 \\
\hline
\end{tabular}

${ }^{a}$ Race/ethnicity was categorized based on self-reported data into Hispanic (including Mexican and non-Mexican Hispanic), non-Hispanic white, non-Hispanic black and other race/ethnicity (Liu et al., 2017).

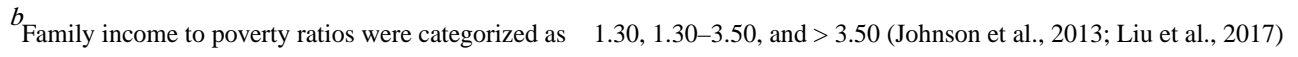

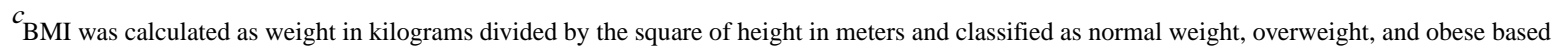
on the CDC's sex-specific 2000 BMI-for-age growth charts for the U.S. Weight and height were determined by trained health technicians according to the NHANES Anthropometry Procedures Manual (WHO, n.d.-b).

CDC, Center for Disease Control and Prevention; BMI, body mass index. 